\title{
Bacterial Isolates and its Antibiotic Susceptibility Pattern in NICU
}

\author{
Shrestha $S,{ }^{1}$ Shrestha NC, ${ }^{1}$ Dongol Singh $S,{ }^{1}$ Shrestha RPB, ${ }^{1}$ Kayestha $S,{ }^{1}$ Shrestha $M,{ }^{1}$ \\ Thakur NK²
}

\author{
${ }^{1}$ Deparment of Pediatrics \\ ${ }^{2}$ Department of Microbiology \\ Dhulikhel Hospital, Kathmandu University Hospital \\ Dhulikhel, Nepal
}

\section{Corresponding Author}

Shrima Shrestha

Department of Pediatrics

Dhulikhel Hospital, Kathmandu University Hospital

Dhulikhel, Nepal

E-mail:sima_shrestha@yahoo.com.

Citation

Shrestha S, Shrestha NC, Dongol Singh S, Shrestha RPB, Kayestha S, Shrestha M et.al. Bacterial Isolates and its Antibiotic Susceptibility Pattern in NICU. Kathmandu Univ Med J 2013;41(1):66-70.

\section{ABSTRACT}

\section{Background}

Neonatal sepsis is one of the major causes of morbidity and mortality among the newborns in the developing world.

\section{Objectives}

To determine the common bacterial isolates causing sepsis in neonatal intensive care unit and its antibiotic susceptibility pattern.

\section{Methods}

A one year discriptive prospective study was conducted in neonatal intensive care unit to analyse the results of blood culture and to look into the sensitivity of the commonly used antibiotics.

\section{Results}

The blood culture yield by conventional method was $44.13 \%$ with nosocomial sepsis accounting for $10.79 \% .84 .08 \%$ were culture proven early onset sepsis and $15.95 \%$ were late onset sepsis. Klebsiella infection was the commonest organism isolated in early, late and nosocomial sepsis but statistically not significant. Gram positive organisms were $39.36 \%$ in which Staphylococcus aureus was the leading microorganism followed by coagulase negative staphylococcus areus. Gram negative organisms were $60.64 \%$ amongst them Klebsiella was the most often encountered followed by Pseudomonas. The most common organism Klebsiella was $87.5 \%$ and $78.3 \%$ resistance to ampicillin and gentamycin respectively. Among gram negative isolates $87.5 \%$ and $77.2 \%$ were resistance to ampicillin and gentamycin respectively. Among gram positive isolates $58.5 \%$ and $31.5 \%$ resistance were noted to ampicillin and gentamycin respectively. Resistance to cefotaxim to gram negative and gram positive isolates were $87.34 \%$ and $59.35 \%$ respectively.

\section{Conclusion}

Klebsiella is most common organism which is almost resistance to first line antibiotics. Resistance to both gram negative and gram positive isolates among firstline antibiotics and even with cefotaxim is emerging and is a major concern in neonatal intensive care unit.

\section{KEY WORDS}

Antibiotic susceptibility, bacterial isolates, neonates 


\section{INTRODUCTION}

Neonatal sepsis is one of the major causes of morbidity and mortality among the newborns in the developing world. ${ }^{1}$

Babies are more susceptible than mothers and infections in infants are more difficult to detect. ${ }^{2}$ It is estimated that $26 \%$ of newborn infants who die do so as a result of infections that occur around birth. ${ }^{2}$ After the first week of life, infections are the main cause of neonatal death in many countries. These are mostly acquired either in hospital as a complication of treatment for other perinatal conditions, or at home. ${ }^{2}$ Zaidi et al review information about pathogens associated with neonatal sepsis in developing countries. ${ }^{3}$ Community-based data are almost completely lacking for the early neonatal period (ie, newborns in the first week of life). Most published data are from hospitals where Klebsiella species, Escherichia coli (E. Coli), and Staphylococcus aureus (S. aureus) are the most common causes of infection.

Antimicrobial resistance patterns of neonatal pathogens are reported in another paper by Thaver et al. ${ }^{4}$ These authors cite concerns about the emerging resistance of Klebsiella and E. coli to commonly used antibiotics. ${ }^{3,4}$ The surveillance of blood stream pathogens in a hospital is important in monitoring the spectrum of microorganisms that invade the bloodstream and the types of organisms associated with a particular clinical discipline. Such data are often used to alert clinicians to emerging pathogens that may pose a threat to the community.

\section{METHODS}

A discriptive prospective study was conducted in neonatal intensive care unit (NICU) of Dhulikhel Hospital, Kathmandu University Hospital from January 2010 to December 2010. Instituitiona approval was taken for the study. All the case of positive blood cultures was included in the study and skin commensals and contaminats were excluded. Case of early onset neonatal sepsis was defined as an infant who had clinical signs of sepsis if it presents during the first seven days of life and "Late onset" if it occurs after the first week and nosocomial sepsis (nososcomial infection as infections occurring after three days of life which are not directly acquired from mothers genital tract). ${ }^{5}$ If there is deteriorating clinical picture or no response to antibiotic therapy over a reasonable period then repeat cultures was performed. Blood culture sample included a single sample collected from peripheral vein under aseptic conditions. A single specimen of two to three milliliter of blood was collected aseptically for culture from all cases. The specimens were inoculated directly into Brain HeartInfusion broth. The inoculated broth bottles were transported immediately to the department of microbiology and incubated at $37^{\circ} \mathrm{C}$. The subcultures were done on blood and MacConkey agar plates on days 1, 2, 3, 5, and 7. The colonies isolated were identified by their colonial morphology. Gram's stain, conventional biochemical tests. Antibiotic resistance pattern of the isolates was studied by using Modified Kirby Baur disc diffusion technique. Proven sepsis was diagnosed, when in addition to the clinical and laboratory signs of sepsis a true pathogen (except coagulase-negative staphylococci species (CoNS) that had to be isolated from at least two different specimens or with only one positive culture adequate antibiotic treatment had to be given for more than 72 hours) was isolated from a normally sterile body fluid. ${ }^{6}$

After obtaining blood for culture, the neonates were administered intravenous ampicillin and gentamycin as the first line of antibiotics. Antibiotic therapy was continued or changed based on the isolation of organisms in the blood culture and sensitivity pattern. This study was undertaken to determine the profile and antibiotic sensitivity pattern of aerobic isolates from blood culture of neonates in NICU. Data were analysed using SPSS 17.

\section{RESULTS}

During the one year study period 213 neonates (male:female=1.5:1) were screened for sepsis.

Among our neonate, low birth weight (LBW) was 115 (54\%) and birth weight $>2500$ gram were $98(46 \%)$. There were $71(33.3 \%)$ preterm and $142(66.7 \%)$ term. Inborn were $166(77.93 \%)$ and out born $47(22.06) \%$. Out of 213 neonates, 107 had positive blood culture but when the contamination / skin commensal were excluded the total number of organism isolated was 94. Among culture positive neonates, 26 were diagnosed as nosocomial culture proven sepsis. The overall incidence of bacteremia was $44.13 \%$. Nosocomial sepsis accounted for $10.79 \%$ of the isolates. Among the 94 culture positive patient $84.08 \%$ were early onset sepsis and $15.95 \%$ were late onset sepsis. Gram negative organisms were 57(60.64\%) and gram positive organisms were $37(39.36 \%)$.

Table 1. Pattern of micro-organisms isolated from blood culture.

\begin{tabular}{|lllll|}
\hline $\begin{array}{l}\text { Micro-organ- } \\
\text { ism }\end{array}$ & $\begin{array}{l}\text { Number } \\
(\%)\end{array}$ & $\begin{array}{l}\text { Early } \\
\text { onset sepsis } \\
(\mathbf{n = 7 9 )}\end{array}$ & $\begin{array}{l}\text { Late onset } \\
\text { sepsis } \\
(\mathbf{n}=15)\end{array}$ & p value \\
\hline Klebsiella & $27(28.72)$ & 24 & 3 & 0.735 \\
\hline S. aureus & $17(18.1)$ & 16 & 1 & 1 \\
\hline Enterobactor & $10(10.6)$ & 8 & 2 & 0.257 \\
\hline CoNS & $9(9.57)$ & 7 & 2 & 0.219 \\
\hline Pseudomonas & $9(9.57)$ & 8 & 1 & 1 \\
\hline E. coli & $6(6.38)$ & 4 & 2 & 0.109 \\
\hline Acinetobactor & $5(5.3)$ & 4 & 1 & 0.408 \\
\hline MRSA & $5(5.3)$ & 5 & 0 & 1 \\
\hline Enterococcus & $3(3.2)$ & 3 & 0 & 1 \\
\hline Streptococcus & $3(3.2)$ & 0 & 3 & 1 \\
sp. & & & 15 & \\
\hline Total & $94(100)$ & 79 & &
\end{tabular}


Table 1 shows distribution of organisms in early and late onset sepsis.

In the early onset sepsis, Klebsiella infection is the most common $(p=0.735)$ followed by $S$. Aureus $(p=1)$, where as in late onset sepsis, Klebsiella and Streptococcus species were the commonest followed by Enterobacter, Coagulase negative staphylococcus species (CoNS) and E coli.

In the gram positive cocci, S. aureus was the leading microorganism followed by CoNS. In the gram negative bacilli Klebsiella was the most often encountered followed by Pseudomonas and Enterobacter.

Among 94 patients, 89 had one episode and five had two episodes of positive blood culture.

Antimicrobial susceptibility of gram positive and nagative isolates are shown in table 2 and 3.

Table 2. Antimicrobial sensitivity pattern of gram negative isolates.

\begin{tabular}{|llllll|}
\hline Antibiotics & $\begin{array}{l}\text { E.coli } \\
\%\end{array}$ & $\begin{array}{l}\text { Klebsi- } \\
\text { ella } \%\end{array}$ & $\begin{array}{l}\text { Pseudo- } \\
\text { monas } \%\end{array}$ & $\begin{array}{l}\text { Entero- } \\
\text { bacter } \\
\%\end{array}$ & $\begin{array}{l}\text { Acineto- } \\
\text { bacter\% }\end{array}$ \\
\hline Ampicillin & NT & 12.5 & NT & 25 & 0 \\
\hline Gentamycin & 50 & 21.7 & 0 & 22.2 & 20 \\
\hline Amikacin & 80 & 88.9 & 11.1 & 100 & 20 \\
\hline Cloxacillin & NT & NT & NT & NT & NT \\
\hline Ciprofloxacin & 50 & 69.9 & 10 & 62.5 & 25 \\
\hline Imepenem & 100 & 100 & 88.9 & 100 & 100 \\
\hline Cefotaxime & 33.3 & 5 & 0 & 25 & 0 \\
\hline Vancomycin & 100 & NT & NT & NT & NT \\
\hline Ceftazidime & NT & 0 & 40 & 0 & NT \\
\hline Piperacillin & NT & 0 & 37.5 & NT & 0 \\
\hline Penicillin & NT & NT & NT & NT & NT \\
\hline Aztreonam & 0 & 0 & 0 & 0 & 0 \\
\hline
\end{tabular}

NT-Not tested

Klebsiella had $87.5 \%$ and $78.3 \%$ resistance to first line antibiotic ampicillin and gentamycin respectively, however it was $100 \%$ sensitive to imepenem and $88.9 \%$ sensitive to amikacin.

Similarly Enterobacter, Enterococcus, Acinetobacter were resistant to ampicillin and gentamycin. Gram negative isolates were mostly sensitive to amikacin except Pseudomonas and Acinetobacter, both mostly sensitive to imipenem. All gram negative isolates were resistant to Aztreonam.

Antibiotic susceptibility of overall gram positive and negative organisms are shown in table 4.

Amikacin has relative better sensitivity to CoNS, S. aureus, methicillin resisstant staphyloccus aureus (MRSA) and enterococcus except streptococcus.

All gram positive isolates had $100 \%$ sensitivity to vancomycin except CoNS where $75 \%$ sensitivity was seen. Ciprofloxacin was other alternative for gram positive isolates except for
Table 3. Antimicrobial sensitivity pattern of gram positive isolates.

\begin{tabular}{|llllll|}
\hline Antibiotics & CoNS $\%$ & $\begin{array}{l}\text { S. aureus } \\
\%\end{array}$ & $\begin{array}{l}\text { Entero- } \\
\text { coccus } \%\end{array}$ & $\begin{array}{l}\text { MRSA } \\
\%\end{array}$ & $\begin{array}{l}\text { Strepto- } \\
\text { coccus. } \\
\text { sp } \%\end{array}$ \\
\hline Ampicillin & 60 & 23.1 & 0 & 0 & 0 \\
\hline Gentamycin & 90 & 85.7 & 50 & 66.7 & 50 \\
\hline Amikacin & 88.9 & 92.3 & 100 & 83.3 & 0 \\
\hline Cloxacillin & 57.10 & 91.7 & NT & 0 & NT \\
\hline $\begin{array}{l}\text { Ciprofloxa- } \\
\text { cin }\end{array}$ & 100 & 80 & 100 & 0 & 100 \\
\hline Imepenem & 0 & 100 & 100 & NT & 100 \\
\hline Cefotaxime & 75 & 67.6 & 0 & 20 & - \\
\hline Vancomycin & 75 & 100 & 100 & 100 & 100 \\
\hline Piperacillin & 0 & 100 & NT & NT & 100 \\
\hline Penicillin & 0 & 0 & NT & NT & 0 \\
\hline Aztreonam & 0 & NT & 0 & NT & NT \\
\hline NT-Not tested & & & & & \\
\hline
\end{tabular}

Table 4. Overall Resistance of Gram negative and Gram positive organisms.

\begin{tabular}{|lll|}
\hline Antibiotics & Gram (-)ve $\%$ & Gram (+)ve \% \\
\hline Ampicillin & 87.5 & 58.5 \\
\hline Gentamycin & 77.22 & 31.5 \\
\hline Amikacin & 40 & 27.1 \\
\hline Cloxacillin & NT & 50.4 \\
\hline Ciprofloxacin & 56.58 & 24 \\
\hline Imipenem & 2.22 & 25 \\
\hline Cefotaxime & 87.34 & 59.35 \\
\hline Vancomycin & 0 & 5 \\
\hline Ceftazidime & 86.7 & NT \\
\hline Piperacillin & 87.5 & 33.4 \\
\hline Penicillin & NT & 100 \\
\hline Aztreonam & 100 & 100 \\
\hline
\end{tabular}

NT-Not tested

MRSA.

\section{DISCUSSION}

The blood culture yield was (99/213) $46.47 \%$. The culture yield is higher than study done in India (18\%) but comparable to the similar study conducted in Western Nepal (44.9\%) but lower than in study in Kathikeyan ( $51 \%$ ) and Tallur et al (64\%)..$^{7-10}$

Gram negative bacteria were the most common organisms isolated in present study accounting $60.64 \%$ and amongst them Klebsiella was the most often encountered followed by Pseudomonas. There are earlier study in agreement to present findings, which reported Klebsiella pneumonie as the most common cause of bacteremia. ${ }^{11,12}$ Mehta et al have reported the incidence of $80.96 \%$ for gram negatives. ${ }^{13}$ Hence, in most of the studies, gram negative bacilli have taken over the gram positive organisms especially in 
hospital settings.

In the early onset neonatal sepsis Klebsiella was commonest followed by S. aureus but statistically not significant. Similar results were shown in Karachi where Klebsiella (39.41\%) and Staphylococcus (24.11\%) were isolated. ${ }^{14}$ Study done by Bhat $\mathrm{Y} R$ showed most common organism in early onset sepsis to be CoNS. ${ }^{7}$ Study by Lee NC showed most common organism in early onset sepsis to be Group B Streptococcus (GBS) however culture was done by Bact/ALERT culture media. ${ }^{15}$ Streptococcus agalactiae (Group B streptococcus, GBS) is the most common cause of neonatal sepsis in many countries, though low rates are reported from many low-income countries, especially those in south Asia. In gram-negative bacilli (Escherichia coli, Klebsiella spp., Pseudomonas spp., Acinetobacter spp.) and gram-positive cocci (such as Staphylococcus aureus and Staphylococcus epidermidis) are other important causes. ${ }^{3,16}$ However, there are many difficulties in interpreting aetiological neonatal sepsis data, because many studies report selected populations of high-risk infants. Specimens from infants in the first 24 hours of life are also seriously under-represented, especially those from low birth-weight babies and babies born outside health facilities. ${ }^{3,17,18}$ Intrapartum antibiotic prophylaxis against S. agalactiae has also led to a substantial change in the bacteria responsible for early onset neonatal sepsis; gramnegative bacilli and Staphylococcus spp. predominate in countries implementing these programs. ${ }^{19}$ However, in our study no cases of GBS has been isolated during the study period.

In late onset neonatal sepsis, in our study Klebsiella and Streptoccus species were common followed by Enterobacter, CoNS and E coli. Study in Karachi showed Klebsiella spesies (57.14\%) followed by Klebsiella pneumonie $(14.28 \%)$ as commonest organism in late onset sepsis. ${ }^{14}$

Study in Kanti Children Hospital showed most common organism as E.coli followed by S. aureus. ${ }^{20}$ However, there was statistically significant predominance of $S$. areus in late onset sepsis. ${ }^{20}$ Study in Patan hospital showed most common organism as CoNS (31\%) followed by Acinetobacter (26.7\%). ${ }^{21}$ Study in Western Nepal showed most common organism in nosocomial as Klebsiella $46 \%$ followed by Enterobacter (15.5\%). ${ }^{8}$ However in our study most common organism causing nosocomial as Klebsiella $36.36 \%$, S. aureus $31.5 \%$. But many authors have reported CoNS to be the most common bacteria in nosocomial infection. $7,22,23$

Study in Patan Hospital showed among gram positive isolates, a significant proportion of both CoNS and nonhemolytic streptococcus were resistant to penicillin, amoxicillin, cloxacillin and cefotaxim. Among gram negative isolates in blood culture significant proportion of the isolates were resistant to commonly used antibiotics cefotaxim. More than $30 \%$ are resistant to cefotaxim and more $50 \%$ are resistant to gentamycin. ${ }^{21}$ In our study among gram negative isolates $87.5 \%$ and $77.2 \%$ were resistance to ampicillin and gentamycin respectively. 58.5\% and $31.5 \%$ of gram positive isolates were resistance ampicillin and gentamycin respectively.

Resistance to cefotaxim to gram negative and gram positive isolates were $87.34 \%$ and $59.35 \%$ respectively hence resistance to third generation cephalosporin is also emerging.

Imipenem had less resistance pattern of only $2.2 \%$ and $25 \%$ in gram positive and negative isolates respectively. All of the gram positive isolates were sensitive to vancomycin and most gram negative organisms were susceptible to amikacin and imipenem similar to the study done by Lee et al. ${ }^{15}$

Polymicrobial sepsis was seen in $5.3 \%$ in our study which is slightly lower than $6.8 \%$ in study by Kumhar GD et al. ${ }^{24} \mathrm{~A}$ combination of ciprofloxacin and amikacin appears to best choice for infection due to Klebsiella as by study done by Kumhar GD et al. ${ }^{24}$

The sensitivity pattern of S. aureus was similar to study done in Western Nepal where $100 \%$ sensitivity to imipenem and vancomycin. Contrast to study in Western Nepal resistant to ciprofloxacin was noted, but only $20 \%$ result was seen in our study and there was negligible resistance to aztreonam but in our study almost all isolates were $100 \%$ resistant. $^{8}$

Treatment by ciprofloxacin is also indicated in multidrug resistant $\mathrm{S}$. aureus in pediatric age group, but its use in neonates is still experimental due to lack of safety and data. ${ }^{9,25}$ Aggarwal $\mathrm{P}$ et al concluded that the evaluated dose resulted in sufficient serum concentrations to eliminate common gram-negative pathogens but would have been insufficient for the treatment of $S$. aureus and Pseudomonas aeruginosa infections. ${ }^{26}$ Multiple regression models adjusting for common neonatal characteristics like weight and gestational age at birth, were used in two studies and found no significant relation between the use of ciprofloxacin and the cartilage size of the right knee measured in ultrasound examination or the height at 12 months corrected age. ${ }^{25,27,28}$

In neonatology, the use of ciprofloxacin in life-threatening infections, although rare, is justified by the fact that clinical benefits largely overweight the potential risks. ${ }^{29}$

\section{CONCLUSION}

Most common organism in early, late and nosocomial sepsis in our set up was klebsiella infection. A low susceptibility to commonly used antibiotics and gentamycin is a cause for concern. The antibiotic susceptibility profile suggested that for a given cohort the initial empirical choice of cloxacillin and in combination with amikacin was more rational. Vancomycin is still the drug of choice for gram positive organisms. Imipenem has good coverage for all gram 
negative and most of the gram positive organisms.

\section{ACKNOWLEDGEMENT}

We would like to thank Mr. Sesgananda Sangel (MPH) for his assistance in statistical analysis.

\section{REFERENCES}

1. Bhutta ZA, Yusuff K. Neonatal sepsis in Karachi: factors determining outcome and mortality. J Trop Pediatr 1997;43:65-70.

2. World Health organisation. Neonatal and perinatal mortality: country, regional and global estimates. WHO report 2006. Geneva, World Health Organisation, 2006.

3. Zaidi AK, Thaver D, Ali SA, Khan TA. Pathogens associated with sepsis in newborns and young infants in developing countries. Pediatr Infect Dis J. 2009 Jan;28(1 Suppl):S10-8.

4. Thaver D, Ali SA, Zaidi AK. Antimicrobial resistance among neonatal pathogens in developing countries. Pediatr Infect Dis $J$ 2009;28:S19-S21.

5. O'Grady NP, Alexander M, Dellinger EP, Gerberding JL, Heard SO, Maki DG et al. Guidelines for the prevention of intravascular catheterrelated infections. Am J Infect Control 2002; 30(8):476-489.

6. Stoll BJ. Infections of the neonatal infant. In: Behrman RE, Kleigman RM, Jenson HB (eds.) Nelson textbook of pediatrics.18th ed. Philadelphia Saunders; 2007.p794-811.

7. Bhat $Y R$, Lewis LE, K E V. Bacterial isolates of early-onset neonatal sepsis and their antibiotic susceptibility pattern between 1998 and 2004: an audit from a center in India. Ital J Pediatr $2011 \mathrm{Jul}$ 11;37:32.

8. Shaw CK, Shaw P, Thapalial A. Neonatal sepsis bacterial isolates and antibiotic susceptibility patterns at a NICU in a tertiary care hospital in western Nepal: a retrospective analysis. Kathmandu Univ Med J (KUMJ) 2007 Apr-Jun;5(2):153-60.

9. Karthikeyan G, Premkumar K. Neonatal sepsis: Staphylococcus aureus as the predominant pathogen. Indian J Pediatr 2001 Aug;68(8):715-7.

10. Tallur SS, Kasturi AV, Nadgir SD, Krishna BV. Clinico-bacteriological study of neonatal septicemia in Hubli. Indian J Pediatr 2000 Mar;67(3):169-74.

11. Kumar S, Rizvi M, Vidhani S, Sharma VK. Changing face of septicaemia and increasing drug resistance in blood isolates. Indian J Pathol Microbiol 2004 Jul;47(3):441-6.

12. Kang $\mathrm{Cl}$, Kim SH, Park WB, Lee KD, Kim HB, Kim EC et.al. Bloodstream infections caused by antibiotic-resistant gram-negative bacilli: risk factors for mortality and impact of inappropriate initial antimicrobial therapy on outcome. Antimicrob Agents Chemother 2005 Feb;49(2):760-6.

13. Mehta M, Dutta P, Gupta V. Antimicrobial susceptibility pattern of blood isolates from a teaching hospital in north India. Jpn J Infect Dis 2005 Jun;58(3):174-6.

14. Mahmood A, Karamat KA, Butt T. Neonatal sepsis: high antibiotic resistance of the bacterial pathogens in a neonatal intensive care unit in Karachi. J Pak Med Assoc 2002 Aug;52(8):348-50.
15. Lee NC, Chen SJ, Tang RB, Hwang BT. Neonatal bacteremia in a neonatal intensive care unit: analysis of causative organisms and antimicrobial susceptibility. J Chin Med Assoc 2004 Jan;67(1):15-20.

16. Zaidi AK, Huskins WC, Thaver D, Bhutta ZA, Abbas Z, Goldmann DA.et al. Hospital-acquired neonatal infections in developing countries. Lancet 2005 Mar 26-Apr 1;365(9465):1175-88.

17. Stoll BJ, Hansen N, Fanaroff AA, Wright LL, Carlo WA, Ehrenkranz RA et.al. Changes in pathogens causing early-onset sepsis in very-lowbirth-weight infants. N Engl J Med 2002 Jul 25;347(4):240-7.

18. Tiskumara R, Fakharee $\mathrm{SH}$, Liu CQ, Nuntnarumit $\mathrm{P}$, Lui KM, Hammoud $M$ et.al. Asia-Pacific Neonatal Infections Study. Neonatal infections in Asia. Arch Dis Child Fetal Neonatal Ed 2009 Mar;94(2):F144-8.

19. Schrag SJ, Hadler JL, Arnold KE, Martell-Cleary P, Reingold A et.al. Risk factors for invasive, early-onset Escherichia coli infections in the era of widespread intrapartum antibiotic use. Pediatrics 2006 Aug;118(2):570-6.

20. Shrestha NJ, Subedi KU, Rai GK. Bacteriological profile of Neonatal Sepsis: A Hospital Based Study. Journal of Nepal Paediatric Society 2011 Jan-April; 31(1):1-5.

21. Shrestha S, Adhikari N, Rai BK, Shreepaili A. Antibiotic resistance pattern of bacterial isolates in neonatal care unit. JNMA J Nepal Med Assoc 2010 Oct-Dec;50(180):277-81.

22. Lin IJ, Chen CH, Chen PY, Wang TM, Chi CS. Nosocomial infection in a neonatal intensive care unit--from a viewpoint of national health insurance. Acta Paediatr Taiwan 2000 May-Jun;41(3):123-8.

23. Kilani RA, Basamad M. Pattern of proven bacterial sepsis in a neonatal intensive care unit in Riyadh-Saudi Arabia: a 2-year analysis. J Med Liban 2000 Mar-Apr;48(2):77-83.

24. Kumhar GD, Ramachandran VG, Gupta P. Bacteriological analysis of blood culture isolates from neonates in a tertiary care hospital in India. J Health PopulNutr 2002 Dec;20(4):343-7.

25. Jick S. Ciprofloxacin safety in a pediatric population. Pediatr Infect Dis J 1997 Jan;16(1):130-3; discussion 133-4: 160-2.

26. Aggarwal P, DuttaS, Garg SK, Narang A. Multiple dose pharmacokinetics ofciprofloxacin in preterm babies. Indian Pediatr 2004;41:1001-1007.

27. Chaudhari S, Suryawanshi P, Ambardekar S. Safety profile of ciprofloxacin used for neonatal septicemia. Indian Pediatr 2004;41:1246-1251.

28. Dutta S, Chowdhary G, Kumar P. Ciprofloxacin administration to verylow birth weight babies has no effect on linear growth in infancy. J TropPediatr 2006;52:103-106.

29. Kaguelidou F, Turner MA, Choonara I, Jacqz-Aigrain E. Ciprofloxacin use in neonates: a systematic review of the literature. Pediatr Infect Dis J 2011 Feb;30(2):e29-37. 